\title{
Access to Healthcare in Urban Family Physician Reform from Physicians and Patients' Perspective: a survey-based project in two pilot provinces in Iran
}

Vahid Kohpeima Jahromi ${ }^{1,2}$, Reza Dehnavieh ${ }^{3}$, Mohammad Hossein Mehrolhassani ${ }^{4}$, Hosain Saberi Anari ${ }^{5}$

${ }^{1}$ Ph.D. Candidate, Department of Health Policy, Management and Economics, Kerman University of Medical Sciences, Kerman, Iran

${ }^{2} \mathrm{Ph}$.D. Candidate, Medical Informatics Research Center, Institute for Futures Studies in Health, Kerman University of Medical Sciences, Kerman, Iran

${ }^{3}$ Associate Professor, Social Determinants of Health Research Center, Institute for Futures Studies in Health, Kerman University of Medical Sciences, Kerman, Iran

${ }^{4}$ Associate Professor, Health Services Management Research Center, Institute for Futures Studies in Health, Kerman University of Medical Sciences, Kerman, Iran

${ }_{5}^{5}$ Assistant Professor, Modeling in Health Research Center, Institute for Futures Studies in Health, Kerman University of Medical Sciences, Kerman, Iran

\section{Type of article: Original}

\begin{abstract}
Introduction: Iran introduced the urban family physician reform, based on the primary healthcare (PHC) approach, in 2012. The reform is restricted to two pilot provinces, which are Fars and Mazandaran and its policymakers request evidence of the reform progress. The study aimed to determine the accessibility of health care in the two pilot sites.

Methods: A cross-sectional study using Primary Care Evaluation Tool (PCET) questionnaires was performed with a multistage stratified cluster sample of the family physicians $(n=141)$ and patients $(n=710)$ in the two provinces between September 2015 and March 2016. The questionnaires contained essential dimensions of health accessibility: organizational, financial, geographical, and cultural access. The data were analyzed by IBM-SPSS software and the descriptive statistics.

Results: With an average population of 2,332, the main daily task for family physicians was patient visits ( $\mathrm{n}=39$ ). Most patients were satisfied with the current hours $(80 \%)$ but visiting a family physician on holidays or after working hours were only rarely possible. The co-payment was an inconvenience to access health services in getting medicines, getting paraclinic exams and a visiting specialist. At least $70 \%$ of patients could receive their preferred healthcare facilities within 40 minutes. The majority of FPs (64\%) believed there were some cultural characteristics in the population that made a limited role for providing better health services.

Conclusion: In the reform the providers were geographically well distributed and some features of the organizational access were relatively high. However there were some difficulties in the financial, cultural, and other features of organizational access.
\end{abstract}

Keywords: Urban family physician, Health care access, Health care reform, PCET, Iran

\section{Introduction}

In a world health report of 2008, the World Health Organization (WHO) urged countries to strengthen primary health care (PHC) for a more efficient, effective and fairer health system (1). Responding to the report, reaction from different countries was varied, governments tried to rethink their roles and responsibilities for their people, thereby changing their health system frame and implementing amended health policies (2). Similarly, Iran introduced

\section{Corresponding author:}

Associate Professor Dr. Mohammad Hossein Mehrolhassani, Department of Health Policy, Management and Economics, Kerman University of Medical Sciences, Haft Bagh Highway, Kerman, Iran.

Tel: +983431325147 Fax: +983431325415, Email: mhmhealth@gmail.com

Received: May 05, 2016, Accepted: September 22, 2016, Published: January 2017

iThenticate screening: July 26, 2016, English editing: October 27, 2016, Quality control: December 01, 2016

(C) 2017 The Authors. This is an open access article under the terms of the Creative Commons Attribution-NonCommercialNoDerivs License, which permits use and distribution in any medium, provided the original work is properly cited, the use is non-commercial and no modifications or adaptations are made. 
impressive reforms toward developing health services based on a PHC approach during the last decade. PHC was carried out with the National Health Network frame. The frame was successful only in rural areas not in large cities (3) and its success was restricted to primary care and not all levels of the health system (4). Responding to the issue, the Iran health system has undergone family physician reform in rural areas and small cities and has launched an urban phase as a pilot in the two Iranian provinces of Fars in the south and Mazandaran in north on the 8th July 2012 (5). The program is aimed to enhance accessibility and quality of the health care system (6). Although accessibility can sometimes be difficult to achieve and there are no standards for defining equitable access internationally $(7,8)$, according to the WHO, it is a key characteristic of a good PHC system (9). Access to health services exemplifies the patients' ability to receive care where and when it is needed (10). In other words, it can be defined as the ease with which health care is obtained (11). In this regard, many writers have defined various health care access barriers such as financial, structural, cognitive (12), and cultural (13). Also, WHO addresses the barriers as geographical (distance to and distribution of family physician), financial (cost-sharing, out-of-pocket payments) and organizational (office hours, distance consultations, waiting times). Based on the observation that reducing barriers to health care access increases its utilization, Iran has tried to implement an equitable PHC for its urban population, and it is conceivable that the government wish to demonstrate the credibility of their efforts, by facilitating the access to health services in the Urban Family Physician Program (UFPP) (14). In a previous study in Iran, improving the access of healthcare was dependent on the implementation of UFPP (15), because having a regular doctor was associated with having better access $(16,17)$. However, after four years since UFPP began, concerns have been raised, and its policymakers request evidence of the reform progress, in order to extend the program to other provinces of the country (18). The evidence can be provided by the results of access of health care evaluation in the piloting stage. So, evaluation of the accessibility of care in the reform is necessary and can provide valuable information on services accessibility and convenience. This study, as the first in this issue, set out to determine the accessibility of health care of UFPP in two pilot provinces of Iran. To achieve this aim, we used an acceptable framework designed by the WHO to insure that access indicators are relevant, and cover key topics accordingly. Also, because access can be understood as a fit between the demand and the supply, we observed the views of both patients and providers.

\section{Material and Methods}

\subsection{Study setting and selection criteria}

This cross-sectional study was conducted between September 2015 and March 2016 in two provinces in Iran, called Fars and Mazandaran. The background to this choice is that Iran is in the middle of a transition towards a nationwide system named Family Physician (FP) and the two selected provinces began the system as a pilot project as mentioned in the introduction. Fars province has three medical universities and is situated in southern Iran while Mazandaran province has two medical universities and is situated in northern Iran. They have a population of approximately 7,600,000 which is $10 \%$ of Iran's population. A multistage stratified cluster sampling of FPs was taken based on lists of active FPs in Fars and Mazandaran provinces made available by the University of Medical Sciences. This resulted in a total sample of 141 FPs ( 87 in Fars; 54 in Mazandaran). In cases of absence, the next FP on the list was included. Response rate was $94 \%$ (distributed: 150, completed: 141). To increase the response rate, one of the researchers (VKJ) traveled to the two provinces and visited the health centers for FPs questionnaires. For the patient questionnaires, multistage stratified cluster sampling was taken and resulted in a total of 710 (431 in Fars, 279 in Mazandaran) targeted patients. It was decided to interview the first five patients of the selected FP on the given data collection day. From the 900 distributed questionnaires, 710 completed questionnaires were returned (Response rate was $78 \%$ ). The personnel who worked the practices/centers asked patients to cooperate with the survey and complete the questionnaire. For both questionnaires, the actual response rate covered our required sample size.

\subsection{Data collection and measurement tool}

We used the Primary Care Evaluation Tool (PCET) which addressed both supply and demand aspects of primary care. It consists of two questionnaires, addressing FPs' situation and views, and patients' experiences. These two questionnaires were introduced by the European Regional Office of the World Health Organization and the Netherlands Institute for Health Services Research (NIVEL) (2). PCET encompasses the four key characteristics of a good PHC system that are part of the service delivery: accessibility, comprehensiveness, coordination and continuity. To assess health accessibility, we applied the accessibility section. The questionnaires were pre structured with precoded answers. The survey approach implies that results related to physicians and their patients rely on their self-reported behaviour or experiences. The FP questionnaire contained 23 items and patient questionnaire contained 31 items on essential dimensions of health accessibility i.e., organizational, financial, geographical, and cultural access. Both questionnaires made the open-ended and close-ended questions. They started 
by demographic part included the variables for FPs and patients: age, sex, profession, level of education and experience.

\subsection{Validity and Reliability of measurement tools}

After the questionnaires were taken from NIVEL via WHO Representative Office in Iran, Validity and Reliability were explored in partnership with the Institute for Future Studies in Health. The questionnaires were translated from the English version to Persian. The validity of the content of the questionnaires was explored by experts who included faculty members of healthcare management, policy-makers, officials, family physicians and national experts. The tools were discussed by the experts and successfully tested in pilot surveys in both provinces. The main content of the tools didn't change. As regards to cultural access being an important issue in Iran, a few questions in the respective field were added. Based on the pilot survey and the extensive feedback given from the experts, changes were made to the tools, and reliability and validity were approved. The reliability of the both instruments were high (Cronbach's alpha $=0.82$ for FP questionnaire, Cronbach's alpha $=0.88$ for patient questionnaire).

\subsection{Data analysis}

The data were entered in the computer using the IBM-SPSS, version 20. Descriptive statistics were computed using PCET guideline. We calculated the reliability coefficient (Cronbach's alpha) of the scales with the software.

\subsection{Ethical consideration}

FPs were asked to complete the questionnaires anonymously. This study was approved and supported by the Kerman University of Medical Sciences (KUMS) and was also accepted by authorities in the universities in studied provinces. Also, it received the approval of the ethics committee of the KUMS.

\section{Results}

\subsection{Demographic and professional characteristics of respondents}

3.1.1. Family physicians:

The survey included 141 family physicians -87 in Fars and 54 in Mazandaran. In both provinces, two thirds of the family physicians were male and one third were female. The average age was $46.7(\mathrm{SD}=8.6)$, with family physicians in Fars a little older than average and family physicians in Mazandaran a little younger. Respondents had little experience as family physicians ( 2.8 years) and their experience as general practitioners was an average 14.9 years. In Mazandaran, almost two thirds of family physicians worked in private office; however, this proportion was $43 \%$ in Fars. In both provinces, most physicians (83\%) were independent, rather than state employed. Most family physicians had not followed any formal training.

\subsubsection{Patients.}

The total number of patients in the study was 710 patients - 431 in Fars and 279 in Mazandaran. The average age of the attending patients was 37 in Fars and 39.4 in Mazandaran. In Fars approximately $75 \%$ of the patients were women and in Mazandaran 59\% were women. 47.5\% of Respondents in Fars had academic education while 43\% in Mazandaran. In the two regions $44 \%$ of patients who filled in the questionnaire were employed. Only a few respondents were unemployed (7\%), retirees (6\%) or unable to work (1.3\%). All of the patients were Muslim.

\subsection{Analysis of health accessibility on urban family physician}

3.2.1. Organizational access

\subsubsection{Workload:}

With an average of 2,332 population, there was high variation in population size ( $\mathrm{SD}=716) .25 \%$ of FPs had fewer than 1,500 population (Table 1). In each province, no more than two FPs said that they served a population of more than 3,500. The main task for FPs was patient visits. Around $81 \%$ of them said they didn't normally make home visits. Patient care made up over $81 \%$ of working hours per week in FPs.

3.2.1.2. Service availability and access:

Most patients were satisfied with the current opening hours (80\%). Visiting an FP on holidays and after working hours was only rarely possible. Usually it was possible to visit an FP the same day in Mazandaran. Making an appointment was uncommon and waiting time was acceptable (Table 2).

\subsubsection{Financial access}

The co-payment was a real obstacle for access to health services from some patients, listed in Table 3 . In Mazandaran, $42 \%$ of the respondents said that they had decided not to visit or delayed a visit to the specialist during the previous year because they could not pay for the visit. In Fars, $41 \%$ had a delay or couldn't pay for the medicines prescribed by FP. Financial difficulty in getting paraclinic exams was $61 \%$ in total. 


\subsubsection{Geographical access}

Almost $90 \%$ of respondents could reach their FP and preferred pharmacists within 40 minutes. Patients in Mazandaran have shorter average travelling time to their healthcare facilities. There are no major regional differences concerning time taken to reach the facilities. At least $70 \%$ of patients can receive their preferred healthcare facilities (maternity, health post, FP, hospital, dentist, and pharmacist) in up to 40 minutes.

3.2.4. Cultural access

Majority of FPs (64\%) believed there were some cultural characteristics in the population that made a limited role for providing better health services. These cultural values and health related beliefs had a greater role in Fars (75\%) than Mazandaran (50\%). Only 30\% of FPs in Fars claimed, patients of the opposite sex tended to visit them. This tendency was greater in Mazandaran (68\%). In both pilot sites, few physicians stated the patients of the opposite sex referred to other physicians of the same sex or excluded from their coverage.

Table 1. Workload and use of time of family doctors

\begin{tabular}{|c|c|c|c|c|c|c|c|}
\hline \multirow{2}{*}{\multicolumn{2}{|c|}{ Aspects of workload }} & \multicolumn{2}{|c|}{ Fars $(n=87)$} & \multicolumn{2}{|c|}{$\begin{array}{l}\text { Mazandaran } \\
(\mathrm{n}=54)\end{array}$} & \multicolumn{2}{|c|}{$\begin{array}{l}\text { Total } \\
(\mathrm{n}=141)\end{array}$} \\
\hline & & Mean & SD & Mean & SD & Mean & SD \\
\hline \multicolumn{2}{|l|}{ Population size } & 2218 & 774 & 2507 & 586 & 2332 & 716 \\
\hline \multicolumn{2}{|l|}{ Patient visits per day } & 40 & 18 & 37 & 15 & 39 & 16 \\
\hline \multicolumn{2}{|l|}{ Health consultations per day } & 7.8 & 6 & 9.5 & 6 & 8.5 & 6 \\
\hline \multicolumn{2}{|l|}{ Home visits per week } & 0.8 & 0.08 & 0.2 & 0.02 & 0.6 & 0.05 \\
\hline \multirow[t]{3}{*}{ Working hours per week spent on: } & Face to face patient visit & 34.9 & 20 & 35.4 & 18 & 35 & 19 \\
\hline & Health consultation & 7.5 & 7 & 9.3 & 7 & 8.2 & 7 \\
\hline & Home visit & 0.13 & 0.02 & 0 & 0.02 & 0.06 & 0.02 \\
\hline \multicolumn{2}{|c|}{ Working hours per week (sum of the numbers above ) } & 42.5 & & 44.7 & & 43.2 & \\
\hline \multirow{2}{*}{\multicolumn{2}{|c|}{ Reading hours per month }} & 21 & 28 & 22 & 21 & 21 & 25 \\
\hline & & $\mathrm{n}$ & $\%$ & $\mathrm{n}$ & $\%$ & $\mathrm{n}$ & $\%$ \\
\hline \multirow{2}{*}{$\begin{array}{l}\text { Reporting staff shortage that has lasted } \\
\text { more than six months }\end{array}$} & Yes & 63 & 74 & 34 & 61 & 97 & 68 \\
\hline & No & 22 & 26 & 22 & 39 & 44 & 32 \\
\hline
\end{tabular}

Table 2. Patients' access and availability of services

\begin{tabular}{|l|l|l|l|l|l|l|}
\hline Aspects of patients' access & \multicolumn{2}{l|}{$\begin{array}{l}\text { Fars } \\
(\mathrm{n}=431)\end{array}$} & \multicolumn{2}{l|}{$\begin{array}{l}\text { Mazandaran } \\
(\mathrm{n}=279)\end{array}$} & \multicolumn{2}{l}{$\begin{array}{l}\text { Total } \\
(\mathrm{n}=710)\end{array}$} \\
\cline { 2 - 8 } & $\mathrm{n}$ & $\%$ & $\mathrm{n}$ & $\%$ & $\mathrm{n}$ & $\%$ \\
\hline Same day visits are possible & 200 & 47 & 192 & 73 & 392 & 57 \\
\hline $\begin{array}{l}\text { Phone number available for patients when center } \\
\text { is closed }\end{array}$ & 98 & 23 & 108 & 41 & 206 & 30 \\
\hline It's possible to visit FP on Friday and holidays & 36 & 9 & 23 & 9 & 59 & 9 \\
\hline $\begin{array}{l}\text { It's possible to visit FP after working hours (at least once per } \\
\text { week) }\end{array}$ & 41 & 10 & 39 & 15 & 80 & 12 \\
\hline At least one FP available when I visit the center & 278 & 66 & 192 & 73 & 470 & 69 \\
\hline Appointment system lasts a long time & 80 & 19 & 40 & 15 & 120 & 17 \\
\hline Waiting time is long before consultation & 97 & 23 & 55 & 21 & 152 & 22 \\
\hline
\end{tabular}

Table 3. Patients reporting obstacles to the use of services related to co-payment and availability of medicines

\begin{tabular}{|l|l|l|l|l|l|l|}
\hline Type of patients problem to pay co-payment in past year & \multicolumn{2}{l|}{$\begin{array}{l}\text { Fars } \\
(\mathrm{n}=431)\end{array}$} & \multicolumn{2}{l|l}{$\begin{array}{l}\text { Mazandaran } \\
(\mathrm{n}=279)\end{array}$} & \multicolumn{2}{l|}{$\begin{array}{l}\text { Total } \\
(\mathrm{n}=710)\end{array}$} \\
\cline { 2 - 8 } & $\mathrm{n}$ & $\%$ & $\mathrm{n}$ & $\%$ & $\mathrm{n}$ & $\%$ \\
\hline Abstinence from visit to FD for financial reasons & 62 & 15.5 & 39 & 15.5 & 101 & 15.5 \\
\hline Abstinence from visit to specialist for financial reasons & 115 & 29 & 99 & 42 & 214 & 34 \\
\hline Financial difficulty in getting medicines prescribed by FD & 163 & 41 & 71 & 32 & 234 & 38 \\
\hline $\begin{array}{l}\text { Financial difficulty in getting paraclinic exams prescribed } \\
\text { by FD }\end{array}$ & 270 & 67 & 109 & 50 & 379 & 61 \\
\hline
\end{tabular}




\section{Discussion}

This study focused on the FPs and patient's opinions regarding the health care accessibility, which has taken place on UFFP reform. FPs and other providers were geographically well distributed in two provinces but there were some barriers in the organizational, financial, and cultural nature of health care accessibility. In organizational access, the study revealed, the number of patient visits per day was high in relation to the population size. In comparison to population size in Western Europe; the daily visits were very high. The other surveys, even in neighboring countries, noted smaller patient consultations per day by FPs $(19,20)$. The high patient visits could bring about shorter consultation time, and insufficient time to communicate with each patient, and this could affect other activities. The study also showed that home visits were rarely made. Home visits can help patients, especially the elderly and patients with disabilities and it can be used as a factor in patient satisfaction with FPs (21). On the patients' point of view, health services availability was beneficial for seeing the FPs the same day, alternative doctors, appointment system and waiting time but there were some problems in opening hours at the weekend, holidays and after working hours. To some extent, this issue could have occurred because of the chronic shortage of staff that presented by FPs. To improve the accessibility, organizational changes in pilot areas is required: reduce the number of face to face visits, greater emphasis on home visits and have a plan to reduce the staff shortages. In a study by Sanchez-Sagrado on primary health care, waiting lists were a major problem in Spain and Sweden (22). Financial costs are the most studied aspect of medical literature and have been shown to be a major barrier to healthcare access (23). In many countries, primary care is officially free of charge but co-payments seem to be an obstacle to the utilization of healthcare services in the study. In the survey, patients answered that they had difficulties with visits to specialists, getting medicines and paraclinic exams prescribed by FPs. However, in a study by Amini and Amiri on financial access to healthcare services during 1983- 2008 in Iran, the financial access has been significantly decreased (24). Regarding this article, it seems there are still some problems in the field, even after running the UFPP reform, particularly in the referral system as reported in a study in Iran (25). By the same token by Ansah EK. et al., removing out-of-pocket payments for health care had an impact on health care-seeking behavior especially among the poorest (26). Introduction of new copayment and a revision of the benefit package of health services may help the issue. Geographical inaccessibility to healthcare is a well-known problem in many developing countries where the physical infrastructure such as transportation and roads may be lacking (27). There is some evidence that the barrier inhibits patients to use primary and secondary care $(28,29)$ and that it is associated with poor health outcomes (30). We showed that most patients could reach their nearest health care facilities and providers in both studied provinces within 40 minutes and that the results are similar to the surveys in Tajikistan, and Belarus (20, 31), although, the travel time in Russia and Turkey has better results. $(19,32)$. In this sense, our results do not confirm the findings of the studies in Iran by Rezaei et al. and Abolhallaje et al. $(33,34)$ that there were significant inequalities in distribution of health care facilities in some provinces and large gaps between the towns in studied areas. It seems that with the implementation of the UFPP, the disparities reported in these studies have declined.

Cultural barriers are one of the reasons of patients' underuse of available care in Asia (35, 36). "A family physician has responsibility to provide full health services to the population regardless of sex, age and other situations" as described by the urban family physician instruction (37). Although culturally appropriate care means, according to Donald Barr et al., that care that does not discriminate based on the racial, ethnicity, and linguistic aspects (13), but the study highlighted just some beliefs in the population that maybe emanated from their religious beliefs. In our study some patients preferred to see the FPs of the same sex instead of their appointed FPs but this factor couldn't convince them to see alternative FPs. This issue can be highlighted more in other provinces where there are ethnicities and different religious beliefs. The literature has identified three strategies to be used by policy makers. The first was to take measures to reduce the staff shortages, so that it may reduce the current high workload of FPs. However, the strategy is more effective in private office (38). The second strategy was to arrange incentive programs for FPs who teach their populations in prevention programs and home visits, and provide opportunities to visit during holidays and after working hours. These two strategies can improve satisfaction and cooperation of patients. The third strategy was to put emphasis on implementation and development of UFPP in second level of care where some patients had financial barriers when using health care services.

\section{Conclusions}

Evaluation of healthcare accessibility in the UFPP showed that geographical access and some features of organizational access were relatively high, and can be compared to the access in other neighboring countries. However, there were some difficulties in the other features of organizational access, financial access in second-level of care and cultural access. Lessons from this evaluation could help policymakers when they seek to enhance access to health services across the country. Further research to clarify differentiation in access between the studied 
http://www.ephysician.ir

provinces and others where the UFPP has not yet been implemented, can help them to make better decisions about their reform.

\section{Acknowledgments:}

This article is a part of $\mathrm{PhD}$ thesis entitled "Analysis of implementation of urban family physician in Iran" which supported by KUMS. The authors are sincerely grateful to Dr. Behjoo, Shiraz Medical Council director and Mr. Bagheri, expert in Mazandaran Medical University for their partnership.

\section{Conflict of Interest:}

There is no conflict of interest to be declared.

\section{Authors' contributions:}

All authors contributed to this project and article equally. All authors read and approved the final manuscript.

\section{References:}

1) World Health Organization. The world report 2008: primary health care now more than ever. WHO. 2008.

2) Boerma WG, Snoeijs S, Wiegers TA, Baltag V. Evaluation of the structure and provision of primary care in the Republic of Moldova: a survey-based project. 2012.

3) Takian A, Rashidian A, Kabir MJ. Expediency and coincidence in re-engineering a health system: an interpretive approach to formation of family medicine in Iran. Health policy and planning. 2010; 26(2): 163-73. doi: 10.1093/heapol/czq036.

4) Heshmati B, Joulaei H. Iran's health-care system in transition. The Lancet. 2016; 387(10013): 29-30. doi: 10.1016/S0140-6736(15)01297-0.

5) Honarvar B, Lankarani KB, Rostami S, Honarvar F, Akbarzadeh A, Odoomi N, et al. Knowledge and practice of people toward their rights in urban family physician program: A population-based study in Shiraz, Southern Iran. International journal of preventive medicine. 2015; 6. doi:10.4103/20087802.158172. PMID: 26124943.

6) Rouhani S, Mohammadpour RA. Family medicine and patients's satisfaction in Iran. Life Sci J. 2012 ; 9 (3): 1840-7.

7) Obrist B, Iteba N, Lengeler C, Makemba A, Mshana C, Nathan R, et al. Access to health care in contexts of livelihood insecurity: a framework for analysis and action. PLoS Med. 2007; 4(10): 1584-8. doi: 10.1371/journal.pmed.0040308.

8) Oliver A, Mossialos E. Equity of access to health care: outlining the foundations for action. J Epidemiol Community Health. 2004; 58(8): 655-8. doi: 10.1136/jech.2003.017731. PMID: 15252067, PMCID: PMC1732867.

9) Boerma WG, Snoeijs S, Wiegers TA, Baltag V. Evaluation of the structure and provision of primary care in the Serbia: a survey-based project. 2010.

10) Gulliford M, Figueroa-Munoz J, Morgan M, Hughes D, Gibson B, Beech R, et al. What does' access to health care' mean? J Health Serv Res Policy. 2002; 7(3): 186-8. doi: 10.1258/135581902760082517. PMID: 12171751.

11) Kelley E, Hurst J. Health care quality indicators project. 2006.

12) Carrillo JE, Carrillo VA, Perez HR, Salas-Lopez D, Natale-Pereira A, Byron AT. Defining and targeting health care access barriers. J Health Care Poor Underserved. 2011; 22(2): 562-75. doi: 10.1353/hpu.2011.0037. PMID: 21551934.

13) Barr DA, Wanat SF. Listening to patients: cultural and linguistic barriers to health care access. Fam Med. 2005; 37(3): 199-204. PMID: 15739136.

14) Rajati F, Kamali K, Parvizy S. Public Health Customers' Experiences of Health Accessibility: A Phenomenological Study. Iranian Journal of Epidemiology. 2011; 7(2): 17-24.

15) Sohrabi MR, Alblushi R. Clients' satisfaction with primary health care in Tehran: A Cross-Sectional Study on Iranian Health Centers. J Res Med Sci. 2011; 16:756-762. PMID: 29091304.

16) Mendoza-Sassi R, Beria JU. Prevalence of having a regular doctor, associated factors, and the effect on health services utilization: a population-based study in Southern Brazil. Cad Saude Publica. 2003; 19: 1257-66. doi: 10.1590/S0102-311X2003000500004. PMID: 14666207.

17) Andersen RM, Yu H, Wyn R, Davidson PL, Brown ER, Teleki S. Access to medical care for low-income persons:how do communities make a difference? Med Care Res Rev. 2002: 59: 384 - 411 . doi: 10.1177/107755802237808. PMID: 12508702. 
18) Honarvar B, Lankarani KB, Ghahramani S, Akbari M, Tabrizi R, Bagheri Z, et al. Satisfaction and dissatisfaction toward urban family physician program: A population based study in Shiraz, Southern Iran. International journal of preventive medicine. 2016; 7:3. doi:10.4103/2008-7802.173793. PMID: 26941904.

19) Kringos DS, Boerma WG, Spaan E, Pellny M, Karakaya K. Evaluation of the organizational model of primary care in Turkey: a survey-based pilot project in two provinces of Turkey. Technical Report. 2008.

20) Boerma WG, Snoeijs S, Wiegers TA, Baltag V. Evaluation of the structure and provision of primary care in Tajikistan: a survey-based project. 2014.

21) Kersnik J. Determinants of customer satisfaction with the health care system, with the possibility to choose a personal physician and with a family doctor in a transition country. Health policy. 2001; 57(2): 155-64. doi: 10.1016/S0168-8510(01)00118-X. PMID: 11395180.

22) Sánchez-Sagrado T. Primary care in Sweden. Semergen. 2016; 42(6): 408-11. doi: 10.1016/j.semerg.2015.09.019. PMID: 26613624.

23) Shook M. Transportation barriers and health access for patient attending a community health center. Field Area paper. 2005.

24) Amini Anabad H, Meskarpour Amiri M. Financial Accessibility of Iranian Households to Health Care Services during 1983-2008. 2013; 16(1): 1-8.

25) Golali-Zadeh E, Moosazadeh M, Amiresmaili MR, Ahangar N. Challenges related to second level of the referral system in family medicine plan: A qualitative research. Medical Journal of the Islamic Republic of Iran. 2012; 29(4): 309-21.

26) Ansah EK, Narh-Bana S, Asiamah S, Dzordzordzi V, Biantey K, Dickson K, et al. Effect of removing direct payment for health care on utilisation and health outcomes in Ghanaian children: a randomised controlled trial. PLoS med. 2009; 6(1): 1000007. doi: 10.1371/journal.pmed.1000007.sd002. PMID: 19127975, PMCID: PMC2613422.

27) Rosero-Bixby L. Spatial access to health care in Costa Rica and its equity: a GIS-based study. Soc Sci Med. 2004; 58(7): 1271-84. doi: 10.1016/S0277-9536(03)00322-8. PMID: 14759675.

28) Jones AP, Bentham G, Harrison BD, Jarvis D, Badminton RM, Wareham NJ. Accessibility and health service utilization for asthma in Norfolk, England. J Public Health Med. 1998; 20(3): 312-7. doi: 10.1093/oxfordjournals.pubmed.a024774. PMID: 9793897.

29) Haynes R, Bentham G, Lovett A, Gale S. Effects of distances to hospital and GP surgery on hospital inpatient episodes, controlling for needs and provision. Soc Sci Med. 1999; 49(3): 425-33. doi: 10.1016/S0277-9536(99)00149-5. PMID: 10414825.

30) Jones AP, Bentham G. Health service accessibility and deaths from asthma in 401 local authority districts in England and Wales, 1988-92. Thorax. 1997; 52(3): 218-22. doi: 10.1136/thx.52.3.218. PMID: 9093335, PMCID: PMC1758521.

31) Boerma WG, Snoeijs S, Wiegers TA, Baltag V. Evaluation of the structure and provision of primary care in Belarus. A survey-based project in the regions of Minsk and Vitebsk. 2009.

32) Boerma WG, Snoeijs S, Wiegers TA, Baltag V. Evaluation of the structure and provision of primary care in Russian Federation. a survey-based pilot project in two rayons of Moscow oblast. 2009.

33) Rezaei S, Matin BK, Karyani AK, Jamshidi K, Zangenah A, Soofi M. Access to healthcare resources in the cities of west of Iran. J Kermanshah Univ Med Sci. 2016; 19(7): 436-5.

34) Abolhallaje M, Mousavi SM, Anjomshoa M, Beigi Nasiri A, Seyedin H, Sadeghifar J, et al. Assessing health inequalities in Iran: a focus on the distribution of health care facilities. Glob J Health Sci. 2014; 6(4): 285-91. doi: 10.5539/gjhs.v6n4p285. PMID: 24999132, PMCID: PMC4825387.

35) Laura L. Cultural barriers to health care for Southeast Asian refugees. Public health reports. 1992 Sep; 107(5):544.

36) Dehnavieh R, Kalantari AR, Sirizi MJ. Urban family physician plan in Iran: challenges of implementation in Kerman. Med J Islam Repub Iran. 2015 November 24; 29:303. PMid: 26913266, PMCID: PMC4764283.

37) Family physician and referral system instruction in urban. Iranian ministry of health and medical education \& Ministry of labor and social affairs; version 2. Tehran: 2011.

38) Mehrolhassani MH, Jahromi VK. Application of goal programming to improve human resource allocation for urban family physician plan in Iran. J Heal Manag Informatics. 2016 Jul 3; 3(3):94-9. 